\title{
The interplay between climate change, forests, and disturbances is
}

\author{
Virginia H. Dale ${ }^{\mathrm{a}, *}$, Linda A. Joyce ${ }^{\mathrm{b}}$, Steve McNulty ${ }^{\mathrm{c}}$, Ronald P. Neilson ${ }^{\mathrm{d}}$ \\ ${ }^{a}$ Environmental Sciences Division, Oak Ridge National Laboratory, P.O. Box 2008, Oak Ridge, TN 37831-6036, USA \\ ${ }^{\mathrm{b}}$ USDA Forest Service, Fort Collins, CO 80523, USA \\ ${ }^{\mathrm{c}}$ USDA Forest Service, Raleigh, NC 27606, USA \\ ${ }^{\mathrm{d}}$ USDA Forest Service, Pacific Northwest Research Station, Corvallis, OR 97331, USA
}

Received 21 November 1999; accepted 25 March 2000

\begin{abstract}
Climate change affects forests both directly and indirectly through disturbances. Disturbances are a natural and integral part of forest ecosystems, and climate change can alter these natural interactions. When disturbances exceed their natural range of variation, the change in forest structure and function may be extreme. Each disturbance affects forests differently. Some disturbances have tight interactions with the species and forest communities which can be disrupted by climate change. Impacts of disturbances and thus of climate change are seen over a board spectrum of spatial and temporal scales. Future observations, research, and tool development are needed to further understand the interactions between climate change and forest disturbances. (c) 2000 Elsevier Science B.V. All rights reserved.
\end{abstract}

Keywords: Drought; Fire; Hurricanes; Introduced species; Outbreaks; Storms

Climate change is predicted to affect future forest conditions by altering forest processes (Aber et al., 2000, in review) and biodiversity (Hansen et al., 2000, in review). While economic

\footnotetext{
The submitted manuscript has been authored by a contractor of the US Government under contract No. DE-AC0500OR22725. Accordingly, the US Government retains a nonexclusive, royalty-free license to publish or reproduce the published form of this contribution, or allow others to do so, for US Government purposes.

* Corresponding author. Tel.: +1-365-576-8043; fax: +1365-576-8543.

E-mail address: vhd@ornl.gov(V.H. Dale).
}

forces may compensate for some monetary repercussions of climate change impacts on forests, changes in productivity, carbon sequestration, forest water resources and the way people relate to the forests (such as recreation) may be less resilient to change (Irland, 2000, in review). However, all of these impacts are moderated by interactions between climate, disturbances, and forests (Dale et al., 2000, in review). Therefore, it is important to understand how particular disturbances influence forests and are affected by climate change (Fig. 1). This special feature of the Science of the Total Environment focuses on seven disturbances common to forests and explores how 


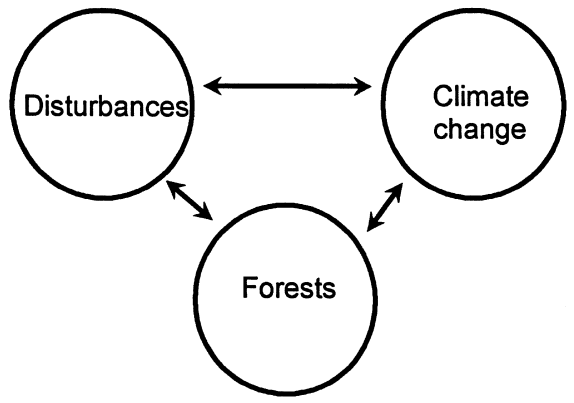

Fig. 1. The interaction between climate change, disturbances, and forests.

these disturbances affect forests and how they may be altered by climate change. These key forest disturbances are fire, drought, introduced species, insect and pathogen outbreaks, hurricanes, wind storms and ice storms.

Disturbances are a natural and integral part of forest ecosystems. The process of forest succession occurs only in the aftermath of disturbances. Some forest species exist solely in disturbed sites. For example, long-leaf pine forests depend on low intensity fires every few years which reduce hardwood ingrowth and kill seedlings of other competing pine species. But when disturbances exceed their natural range of variation, the change in forest structure and function may be extreme [as Ayres and Lombardero (2000, this issue) discuss for pests and pathogens]. Furthermore, the frequency, size, intensity, seasonality, duration, and type of the disturbances often depend on weather and climate in addition to site characteristics [as reviewed for wind storms by Peterson (2000, this issue)] (Fig. 1). The Yellowstone fire of 1988 burned over 250000 ha due to the prolonged drought and high winds (Renkin and Despain, 1992). As a long-term phenomenon, climate change is likely to interact with other types of forest disturbance.

Impacts of disturbances are seen over a broad spectrum of spatial scales, including those of the leaf, the tree, the forest, and the forested landscape. Disturbances can reduce leaf function, deform tree structure, cause tree death, alter regeneration patterns by destroying seed banks, disrupt the physical environment via soil erosion or nutri- ent loss, and increase landscape heterogeneity such as patchiness of forest communities. Introduced invasive species can impact forest ecosystems through herbivory, predation, habitat destruction, competition, loss of gene pools through hybridization with natives, and disease by either causing or carrying the disease. Outbreaks of native insects and diseases can result in similar impacts on forests. At the scale of a forest stand, introduced species as well as outbreaks of native insects and diseases can alter natural processes, such as nutrient cycles, and fire frequency and intensity.

Some disturbances have tight interactions with the species and forest community. Some tree species have developed mechanisms of adaptation as a result of the repeated occurrence of these disturbances over time. Thick bark on some species allows their survival in ground-level fires. Repeated ground-level fires in western forests, reduce intermediate-height vegetation which can serve as fuel between the surface and the crown. Thus these repeated ground-level fires reduce the occurrence of stand-killing crown-level fires.

Each disturbance affects forests differently. Some cause large-scale tree mortality, whereas others affect community structure and organization without causing massive mortality (e.g., ground fires). Forest disturbances influence how much carbon is stored in trees or dead wood. All these natural disturbances interact with humaninduced effects on the environment, such as air pollution and land-use change resulting from resource extraction, agriculture, urban and suburban expansion, and recreation. Some disturbances can be functions of both natural and human influences (e.g., forest fire ignition and spread).

A challenge to understanding effects of climate change on forests is not only obtaining information on the impacts of temperature and precipitation on forests but also acquiring knowledge about how climate change affects disturbance and how disturbances affect the forest system (Fig. 1). The outcomes of disturbance impacts on forests are often not easy to predict [e.g., Lugo (2000, this issue) presents 12 possible outcomes of hurricanes in tropical forests]. Furthermore, new disturbances, such as the invasion and spread of 
introduced species can cause heretofore unforeseen effects on forests (Simberloff, 2000, this issue).

Forests affect climate as well. Predicted climate changes are thought to result from increasing concentrations of atmospheric $\mathrm{CO}_{2}$ and to be gradually warming the planet (Houghton et al., 1996). About a quarter of the increase in atmospheric $\mathrm{CO}_{2}$ comes from deforestation, and thus forest distribution has an impact upon global climate (Fig. 1). On local, regional and global scales, the distribution of trees can affect precipitation patterns (Shukla and Sellers, 1990; Foley et al., 1998; Pielke et al., 1998).

The link between climate change and disturbances needs to be formally integrated into our understanding of climate change. There are relatively few field studies on how climate change interacts with forest disturbances. Fires and droughts are the cases where such interactions have been explored with field experiments (Flannigan et al., 2000, this issue; Hanson and Weltzin, 2000, this issue). Nevertheless, we believe it is essential to use a diversity of tools to explore all interactions between climate change and these forest disturbances. Key tools for understanding impacts of climate change are spatially-explicit models that build upon monitoring data on impacts of climate on disturbances, methods of observing effects of both climate and disturbances upon the function, structure, and composition of ecological systems, and field, laboratory, and greenhouse experiments that explore these relationships. Models are needed to predict impacts of future climate change on the environment because future precipitation and temperatures are likely to be very different from the conditions experienced in the past.

Translating climate change to forest impacts requires an understanding of the spatial distribution of the changes in precipitation and temperature because each forest type responds to climate in unique ways, partially dependent upon their current environmental conditions. General Circulation Models (GCMs) are often used to project the spatial distribution of change in climate conditions. However, few models are available to project how climate change affects the frequency, intensity, extent, or duration of disturbances. In the articles that follow, fire hazard was the only disturbance analyzed under different climate scenarios (Flannigan et al., 2000, this issue). Environmental models that can project the impact of these changes in disturbances onto forest dynamics are also rare. However, enough attention has been paid to modeling drought effects on forests that Hanson and Weltzin (2000, this issue) call for coupling better climate predictions at regional scales with field-based experiments based on their review of modeling approaches.

Such interactions between climate, disturbances, and forest systems may be critical in determining how climate change expresses its effects on forests. For example, changes in species diversity are most quickly apparent after a disturbance has cleared the landscape and species adapted to the new climate become established. Because forests are so long-lived, it may be that many climate change effects on forests are most easily observed in places where the successional pathway has been disrupted by a disturbance. Forest management practices may be implemented so that managed forests can deal with new disturbance regimes under climate change. For example, trees with thick bark can be planted in fire-prone sites or forests can be thinned to increase tree survival during drought.

This set of papers documents areas where research is needed to further our understanding of the interactions between climate change and forest disturbances. The need for disturbance models and field experiments has already been mentioned. In addition, there is a clear need for better understanding of how climate conditions affect disturbance regimes (their frequency, intensity, duration, and extent). Developing this understanding will require climate projections at a scale relevant to forest disturbances as well as better data on disturbance impacts. At the same time, a better understanding of how disturbances affect microclimate needs to be developed. Finally, the interactions between forest management and disturbance need to be improved, for human actions can impede, mitigate or facilitate the interactions. In summary, we see that the interactions between climate change and forest 
disturbance are an important area of research and hope that this set of papers will stimulate further thought and research activities.

\section{Acknowledgements}

This project was supported by the US Global Change Research Program's National Assessment of Climate Change, the USDA Forest Service Global Change Research Program, and the Department of Energy. Oak Ridge National Laboratory is managed by the University of TennesseeBattelle LLC for the US Department of Energy under contract DE-AC05-00OR22725. This paper is Environmental Sciences Division Publication Number 4953.

\section{References}

Aber J, Neilson R, McNulty S, Lenihan J, Bachelet D, Drapek $\mathrm{R}$. Forest processes and global environmental change: predicting the effects of individual and multiple stressors. BioScience 2000 (in review).

Ayres MP, Lombardero MJ. Assessing the consequences of global change for forest disturbances for herbivores and pathogens. Sci Total Environ 2000 (this issue).

Dale VH, Joyce LA, McNulty S et al. Forest disturbances and climate change. BioScience 2000 (in review).
Flannigan MD, Stocks BJ, Wotton BM. Climate change and forest fires. Sci Total Environ 2000 (this issue).

Foley JA, Levis S, Prentice IC, Pollard D, Thompson SL. Coupling dynamic models of climate and vegetation. Global Change Biol 1998;45:61-579.

Hansen AJ, Neilson RP, Dale VH et al. Global change in forests: interactions among biodiversity, climate, and land use. BioScience 2000 (in review).

Hanson P, Weltzin J. Drought, forests, and climate change. Sci Total Environ 2000 (this issue).

Houghton JT, Meira-Filho LG, Callander BA, Harris N, Kattenberg A, Maskell K, editors. Climate change 1995: the science of climate change. New York: Cambridge University Press, 1996.

Irland LC. Ice storms and forest impacts. Sci Total Environ 2000 (this issue).

Lugo AE. Effects and outcomes of hurricanes in a climate change scenario. Sci Total Environ 2000 (this issue).

Peterson CJ. Catastrophic wind damage to North American forests and the potential impact of climate change. Sci Total Environ 2000 (this issue).

Pielke RA, Avissar R, Raupach MR, Dolman AJ, Zeng X, Denning AS. Interactions between the atmosphere and terrestrial ecosystems influence on weather and climate. Global Change Biol 1998;44:61-475.

Renkin RA, Despain DG. Fuel moisture, forest type and lightning-caused fire in Yellowstone National Park. Can J Forest Res 1992;22:37-45.

Simberloff D. Global climate change and introduced species in forests. Sci Total Environ 2000 (this issue).

Shukla JCN, Sellers P. Amazon deforestation and climate change. Science 1990;47:1322-1325. 